\title{
Preliminary Design for near Real-Time GPS Meteorology over Peninsular Malaysia (G-MeM)
}

\author{
Yusuf Drisu Opaluwa ${ }^{1, *}$, Tajul Ariffin Musa ${ }^{1}$, Abdullah Hisam Omar $^{1}$, Mustafa Din Subari ${ }^{2}$, and Lazarus \\ Mustapha Ojigi ${ }^{3}$ \\ ${ }^{1}$ GNSS and Geodynamics Research group, Faculty of Geoinformation and Real Estate, Universiti Teknologi Malaysia, Malaysia \\ ${ }^{2}$ National Space Agency (ANGKASA), Putrajaya, Malaysia \\ ${ }^{3}$ Mission Planning, IT and Data Management Department, National Space Research and Development Agency, Abuja, Nigeria
}

Received 21 October 2013, revised 20 July 2014, accepted 4 August 2014

\begin{abstract}
This paper presents a conceptual approach for near real time Global Positioning System (GPS) meteorology in Malaysia using combined space- and ground-based GPS observations. Data from a single GPS station is utilised to derive wet refractivities for comparison with radio occultation (RO). This study shows that the wet refractivities from the ground-based GPS present similar patterns and better correlation with the radiosonde data than that from the space-based GPS RO data at altitudes between $0-5 \mathrm{~km}$. Similarly, the wet refractivities derived from RO are more highly correlated with the radiosonde data than the ground-based GPS at altitudes above $5 \mathrm{~km}$. The residual $N_{w}$ vary from $-9.25-21.136 \mathrm{~N}$-unit at $00 \mathrm{~h}$ UTC for the ground-based GPS while for the GPS RO, it is $-19-9.259 \mathrm{~N}$-unit at $00 \mathrm{~h} \mathrm{UTC}$.
\end{abstract}

Key words: Radio occultation, Atmospheric profiling, Equatorial troposphere, Zenith path delay

Citation: Opaluwa, Y. D., T. A. Musa, A. H. Omar, M. D. Subari, and L. M. Ojigi, 2014: Preliminary design for near real-time GPS meteorology over Peninsular Malaysia (G-MeM). Terr. Atmos. Ocean. Sci., 25, 813-826, doi: 10.3319/TAO.2014.08.04.01(A)

\section{INTRODUCTION}

Atmospheric water vapour plays a crucial role in the Earth's energy and hydrological cycles due to its high variability. Hence, information on atmospheric water vapour is essential for predicting global climate changes and rainfall phenomena. However, because of its spatial variability and complexity in time and space, accurate water vapour observations in real time are very challenging (Varmaghani 2012). Several comparative analyses of Global Positioning System (GPS) meteorology with in-situ meteorological observations (e.g., Kursinski et al. 1997; Liou et al. 2006; Rizos et al. 2009) have confirmed its reliability, and hence established the benefits of GPS observations for atmospheric sounding. GPS meteorology is sensitive to the total atmospheric delay of GPS radio signals and hence can provide atmospheric information (e.g., Bevis et al. 1992; Liou et al. 2007; 2010, Lin 2010; Rizos 2012).

In space geodetic positioning an estimate of the tropospheric delay is one of the by-products of GPS data process-

\footnotetext{
* Corresponding author

E-mail: ydopaluwa2@live.utm.my
}

ing. Conventionally, the total delay of GPS radio signals along the line of sight from each satellite are mapped to the zenith direction leading to a single average parameter called the zenith total delay or zenith path delay (ZPD). ZPD is a crucial parameter for meteorological and climatological study (Kuo et al. 2000; Chen et al. 2011). For instance, it serves as an additional input parameter in Numerical Weather Prediction (NWP) models for synoptic meteorology, while for nowcasting; it is a standard real time product used as a measure of the state of the atmosphere (Bosy et al. 2010).

Over the years, ground-based GPS meteorology has been predominantly used to estimate Integrated Water Vapour (IWV) over a GPS site utilising the ZPD, but this approach has limitations in resolving atmospheric refractivity in the upper troposphere and lacks the capability to profile the atmosphere. Alternatively, the space-based GPS radio occultation (RO) technique has been developed, providing global coverage with a capability to generate atmospheric refractivity profiles. However, it has limitations in resolving the lower tropospheric refractivity.

Unfortunately, the lower tropospheric region presents 
the greatest atmospheric uncertainties, and these conditions are usually more severe in the equatorial region due to high vapour content and variations in the equatorial troposphere. However, the region is yet to be adequately studied. Hence; there is the need for optimal profiling of the vertical structure of the equatorial tropospheric column. The equatorial region, otherwise known as the low latitude or tropical region, is exposed to intensive sunlight all year round due to the relatively low zenith distance of the sun in the region, with temperatures in the ranges $20^{\circ}-35^{\circ} \mathrm{C}$ (Musa et al. 2011). Since water vapour is responsible for atmospheric stabilisation, the warmer the air, the more water vapour it can hold to form droplets that eventually produce rain. This circumstance is responsible for the peculiar atmospheric dynamics and climatic uncertainty in the tropics. This great uncertainty has hitherto limited the ability of global circulation models to properly resolve the atmospheric dynamics in the tropical region.

The challenge therefore is to precisely determine the tropospheric column vapour budget and its spatial distribution in real time. Located in the tropical equatorial region, Peninsular Malaysia experiences bi-monsoonal seasons; these are the North-East monsoon (November to early March) and the South-West monsoon (early May to August). The two monsoons bring heavy rain, which sometimes causes extensive flooding in the country. In general, the mean monthly rainfall in this region indicates drier weather conditions from May to early July and wetter conditions from November to January (Musa 2007). Therefore, the monsoon seasons highly influence the rainfall distribution in the area. Consequently, the climate and weather conditions in the country reflect the strong influence of the atmospheric water vapour. In view of this, it is appropriate to develop a strategy for optimal estimation of atmospheric water vapour over Peninsular Malaysia. This paper discusses the proposed approach for GPS atmospheric sensing in Peninsular Malaysia through the integration of space- and ground-based GPS observations. Hence the concept of G-MeM relies on a combination of GPS RO measurements with ground-based GPS observations.

\section{GPS RADIO OCCULTATION TECHNIQUE}

As described in Wickert et al. (2004), the RO technique uses dual-frequency carrier phase measurements (L-band) made by a GPS receiver installed on a Low-Earth-Orbiting (LEO) satellite, tracking a setting or rising GPS satellite. Combining these measurements with the satellites position and velocity information, the phase path increase due to the atmosphere during the occultation event can be derived. The bending angle of the signal path is a key measurement for GPS RO and is induced by ionospheric and neutral atmospheric refraction (Lin 2010). The vertical profiles of bending angle and refractivity, temperature, pressure and water vapour in the neutral atmosphere can be derived from the raw RO measures of the excess Doppler shift to the radio signal transmitted by the GPS satellite (Kursinski et al. 1997; Lin 2010). The dry and wet retrieval products can be generated from the refractivity profiles. Several comparisons of GPS RO and in-situ meteorological observations (e.g., Xie et al. 2010; Kishore et al. 2011; Kursinki et al. 2012) have demonstrated its reliability and benefits for atmospheric sounding.

Liou et al. (2010) observed that information about the atmosphere and ionosphere for meteorology, climatology and geophysics required a global coverage of the earth surface by RO measurements as well as high accuracy measurements and usage of radio signals in different frequency bands. However, the global coverage can only be realised by using many satellites transmitting radio signals. Furthermore, it is required that the atmospheric sounding period over a certain region should be shorter than the time scale of the changes in the atmospheric state, while the measurement frequency in any region should correspond to the frequency of observations. These requirements can be satisfied by a system of high orbital satellites with long orbital period and low orbital satellites Liou et al. (2010), hence, the configuration of the GPS satellites and LEOs fulfil these conditions.

For each occultation event, the GPS RO data analysis is carried out in three main steps (Mousa and Tsuda 2001; 2012):

Step 1. Derivation of the atmospheric bending angle: In geometric optics theory, a ray passing through the atmosphere behaves according to Fermat's Principle of Least Time. The ray travel path is a curve defined by the expression:

$r n(r) \sin \phi=$ cons $\tan t=a$

where $r$ is the distance from the origin of symmetry to a point on the ray path, $\phi$ is the angle between the direction of $r$ and the tangent to the ray path, and $n$ is the refractive index at $r$. Equation (1) corresponds to Snell's Law in polar coordinates for a spherically symmetric medium, and is otherwise; known as Bouguer's Formula (Lowry et al. 2002; Mousa and Tsuda 2012).

The phase path between the receiver and transmitter on a ray can be obtained explicitly for the radio signal between a receiver Eq. (1) and transmitter Eq. (2) as (Lowry et al. 2002):

$L=\int_{1}^{2} n(r) d l$

where $d l=\sqrt{d r^{2}+r^{2} d \theta^{2}}$ is in polar coordinates and $\theta$ is the spherical angle between the transmitter and receiver.

If $G$ is the straight-line geometrical path length of the radio signal through the atmosphere, the excess path length between the transmitter and the receiver can be written as (Bevis et al. 1992): 
$\Delta L=\int_{L} n(r) d l-G$

$G=\sqrt{r_{1}^{2}+r_{2}^{2}-2 r_{1} r_{2} \cos \theta}$

Given that $d r=d l \cos \alpha$ and using Eqs. (1) and (2) may be re-written as

$L=\frac{r n^{2}(r)}{\sqrt{r^{2} n^{2}(r)-a^{2}}} d l=\int_{x_{1}}^{x_{2}} \frac{\left[1-\frac{x}{n} \frac{d n}{d x}\right] x}{\sqrt{x^{2}-a^{2}}} d x$

where $x=n r$ is the re-fractional radius. On this basis, a signal travelling in a spherically symmetric medium will bend by an angle $\alpha$ (Born and Wolf 1999):

$\alpha=-2 a \int_{a}^{\infty} \frac{1}{n \sqrt{n^{2} r^{2}-a}} \frac{d n}{d r} d r$

where $a$ is the impact parameter of the ray and can be obtained in practice from Eq. (1) as:

$r_{t} n_{t} \sin \left(\Psi_{t}+\delta_{t}\right)=r_{r} n_{r} \sin \left(\Psi_{r}+\delta_{r}\right)=a$

where $\Psi_{t}, \Psi_{r}, \delta_{t}$, and $\delta_{r}$ are derived from $\phi_{r}$ and $\phi_{t}$ as shown in Fig. 1.

Thus, the total bending of the ray $\left(\alpha=\delta_{t}+\delta_{r}\right)$ can be derived as a function of the impact parameter $(a)$, such that the bending angle $(\alpha)$ is the fundamental function to be inverted in occultation processing. The bending angle $\alpha$ is derived from the L1 and L2 phase delay of the GPS. The excess delay due to the atmosphere can then be isolated using the position of the transmitter $\left(r_{t}\right)$, the receiver $\left(r_{r}\right)$ and their clocks (Fig. 1).

The atmospheric excess phases are obtained using the GPS double-differencing approach (Wickert et al. 2001). This utilises ground GPS data with a non-occulting reference GPS satellite in RO data processing in order to eliminate some systematic errors. However, the zero-differencing technique can also be used (Arras 2010; Wickert et al. 2012). The RO geometry for the zero-differencing approach is depicted in Fig. 2.

The excess atmospheric Doppler can be derived from atmospheric excess delay as a function of time.

This excess atmospheric Doppler is related to the signal bending as (Liou et al. 2010; Mousa and Tsuda 2012):

$\Delta f=-f / c\left(V_{t}^{r} \cdot \cos \Phi_{t}+V_{r}^{r} \cos \Phi_{r}-V_{r}^{T} \cdot \sin \Phi\right)$

where $f$ is the GPS transmitter frequency, $c$ is the speed of light, and $V_{t}$ and $V_{r}$ are the transmitter and receiver velocity vectors respectively. The superscript $r$ and $T$ are the radial and tangential component of the velocity vector respec- tively. $\Phi_{r}$ and $\Phi_{t}$ are the angles between the ray path and the direction of $r$, for both the receiver and the transmitter respectively.

Step 2. Retrieval of the refractivity profile: The most popular inversion technique for atmospheric data retrieval using RO is the Abel inversion or transform. This has been widely used in seismic and astronomical inversions (e.g., Kursinski et al. 1997). The process involves using the Abel inversion to invert the bending angle obtained from GPS Doppler shift [Eq. (5)] to derive the refractive index as (Hajj et al. 2002; Mousa and Tsuda 2012):

$n(x)=\exp \left[\frac{1}{\pi} \int_{a}^{\infty} \frac{\alpha(a)}{a^{2}-x^{2}} d a\right]$

where $x=n r$.

Step 3. Retrieval of atmospheric parameters: Finally, the atmospheric parameters; density $(\rho)$, pressure $(P)$, temperature $(T)$, and/or water vapour $(e)$ are derived from the refractivity profile using (Thayer 1974):

$$
\begin{aligned}
N & =(n-1) 10^{6} \\
& =k_{1}\left(P_{d} / T\right) Z_{d}^{1}+k_{2}\left(P_{v} / T\right) Z_{v}^{1}+k_{3}\left(P_{v} / T^{2}\right) Z_{v}^{1}
\end{aligned}
$$

where $Z_{d}^{-1}$ and $Z_{v}^{-1}$ are the inverse compressibility factors for dry air and water vapour, respectively. The refraction

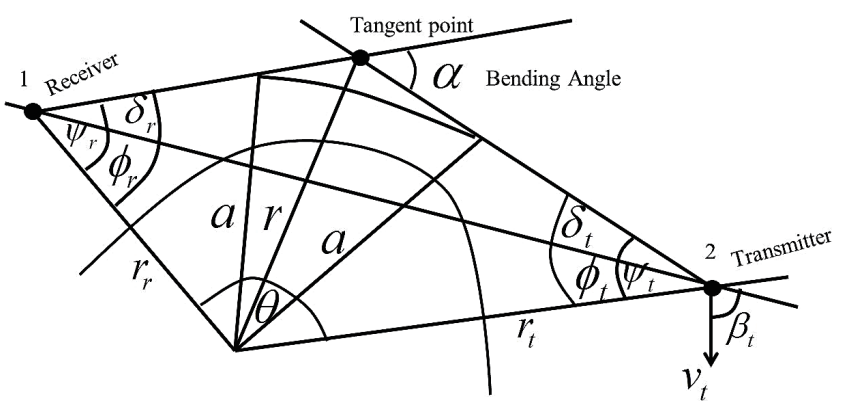

Fig. 1. A schematic diagram defining the geometrical variables for a GPS transmitter/receiver link.

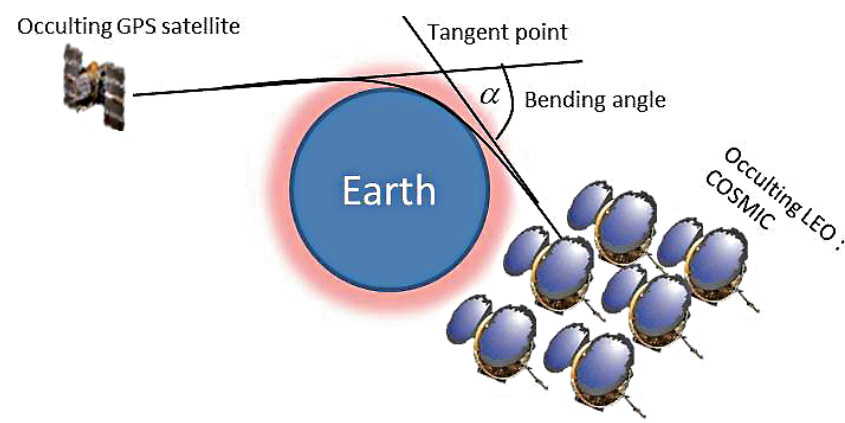

Fig. 2. GPS RO (zero-differencing geometry) with the LEO satellites. 
coefficients for Eq. (9) are given by Bevis et al. (1994) as:

$$
\begin{aligned}
& k_{1}=(77.604 \pm 0.05) \text { Kmbar }^{-1} \\
& k_{2}=(70.4 \pm 2.2) \text { Kmbar }^{-1} \\
& k_{3}=(3.739 \pm 0.012) \times 10^{5} K^{2} \text { mbar }^{-1}
\end{aligned}
$$

The first term on the right-hand-side of Eq. (9) is the dry term, while the second and the third are the wet terms (Healy and Eyre 2000; Foelsche and Kirchengast 2001; Lin 2010). A detailed description of the RO principle (measurements, retrieval of atmospheric parameters as well as procedures for error mitigation) can be found in (Hajj et al. 2002; Liou et al. 2010).

\section{GROUND-BASED GPS ATMOSPHERIC PROFILING}

Several studies (e.g., Bevis et al. 1992; Liou et al. 2001; de Haan et al. 2009; Rizos et al. 2009) demonstrated the efficiency of ground-based GPS meteorology, especially in neutral atmospheric sensing, but the atmospheric profiling concept from ground-based GPS observations became popular following the development of GPS tomography for 3-D and 4-D variational tropospheric analysis, as well as retrieval of the horizontal and vertical refractivity field (e.g., Hirahara 2000; Flores et al. 2000; Davies et al. 2001; Macdonald et al. 2002).

Lowry et al. (2002) examined the feasibility of estimating the atmospheric refractivity structure using ray propagation models to fit GPS-derived tropospheric delay using a least squares method. They concluded that ground-based GPS provides useful atmospheric refractivity structure constraints despite its limited vertical resolution which was attributed to the limitations of the inverse method with a significant portion representing the spatial inhomogeneity of the atmosphere. They recommended that future efforts should attempt to minimise the spatial and temporal variation between GPS and in-situ measurements.

Similarly, Lin et al. (2011) generated tropospheric refractivity profiles from a single GPS site in Shanghai, China using the exponential wet refractivity distribution concept proposed by Bean (1961). The GPS Precise Point Positioning (PPP) technique was used for high accuracy zenith wet delay (ZWD) estimation. The equivalent height of the wet term $H_{\mathrm{w}}$ was the key parameter of the wet refractivity profile model and the golden section search method (GSSM) was used to search for $H_{w}$ to generate the wet refractivity profiles. The profile from GPS and the Hopfield model was compared using profiles from radiosonde as control values. It was reported that the GPS retrieved refractivity profiles showed better correlation with the radiosonde profiles at elevations below $5 \mathrm{~km}$. However, they suggested that atmospheric refractivity retrieval of this kind should be based upon slant path delay (SPD) since it increases in value with a decrease in elevation angle.

There are several empirical and semi-empirical refractivity profile models such as the Hopfield model. Hopfield (1969) gave the refractivity in the neutral atmosphere at height $h(\mathrm{~m})$ as:

$$
\begin{aligned}
& N_{h}(h)=N_{h}^{0}\left(\frac{H_{h}-h}{H_{\text {tropo }}-H}\right)^{4} \\
& N_{w}(h)=N_{w}^{0}\left(\frac{H_{\text {tropo }}-h}{H_{\text {tropo }}-H}\right)^{4}
\end{aligned}
$$

$H_{h}=\left(40136+148.72 t_{s}\right) \mathrm{m}$

$H_{\text {tropo }}=11000 \mathrm{~m}$

where $t_{s}$ is the surface temperature, $N_{h}^{0}$ and $N_{w}^{0}$ are the surface hydrostatic and the non-hydrostatic or wet refractivity term respectively, $H$ is the surface height above mean sea level while, $H_{h}$ and $H_{\text {tropo }}$ are the heights of neutral atmosphere and troposphere respectively.

Bean (1961) proposed a dual-exponential model for wet term of refractivity:

$N(h)=N_{d}^{0} \exp \left(-h / H_{d}\right)+N_{w}^{0} \exp \left(-h / H_{w}\right)$

where $H_{d}$ and $H_{w}$ are the equivalent heights of the dry and wet term of refractivity, respectively. Following Thayer (1974), the wet refractivity in the vertical direction is assumed to obey exponential distribution hence;

$N_{w}(h)=N_{w}^{0} \exp \left(-h / H_{w}\right)$

This distribution is assumed to represent the average condition of wet refractivity distribution in the troposphere. Therefore, in the neutral atmosphere, the ZWD is the integral of the wet term of refractivity $\left(N_{w}\right)$ in zenith path. Thus, we have (Lin et al. 2011):

$$
\begin{aligned}
\mathrm{ZWD} & \left.\approx \mathrm{ZWD}\right|_{\text {tropo }}=10^{-6} \int_{0}^{H_{\text {ropo o }}} N_{w}(h) d h \\
& =10^{-6} H_{w} N_{w}^{0}\left[1-\exp \left(-\frac{H_{\text {tropo }}}{H_{w}}\right)\right]
\end{aligned}
$$

ZWD is also a function of $H_{w}$ which can be obtained using a searching algorithm (Lin et al. 2011). For $H_{w}$ less than $3 \mathrm{~km}$, the term in brackets on the right hand side of Eq. (15) approaches one (1), while $H_{\text {tropo }}$ is usually near or greater than $11 \mathrm{~km}$. Thus, the ZWD may be approximated as:

$\mathrm{ZWD} \approx 10^{-6} H_{w} N_{w}^{0}\left[1-\exp \left(-\frac{H_{\text {tropo }}}{H_{w}}\right)\right] \approx 10^{-6} H_{w} N_{w}^{0}$ 
Equations (15) and (16) indicate that ZWD is an increasing function of $H_{w}$. In general, for a moderate climate, $H_{w}$ can also be approximated as:

$$
H_{w} \approx \frac{\mathrm{ZWD}}{10^{-6} N_{w}^{0}}
$$

Nevertheless, Liou et al. (2010) affirmed that the real profiles $N(h)$ may differ from the exponential dependence and gave a more accurate form of vertical refractivity profile as:

$$
N(h)=N_{0} \exp \left(-a_{1} h^{2}-b_{1} h\right)
$$

where $N_{0}$ is the near-surface refractivity,

$$
b_{1}=-\frac{1}{10} \ln \left(\frac{9.2 \times 10^{-5}}{N_{0}}\right)
$$

But they observed that this relation [Eq. (18)] does not account for the refractivity features at the tropopause and troposphere due to the continuous presence of vapour.

\section{THE INTEGRATION APPROACH}

Foelsche (1999) observed that water vapour imaging using a combination of ground- and space-based GNSS data can only be achieved if individual occultations are collocated with a ground GNSS receiver network. This condition usually occurs intermittently in time with a single or a few LEO satellites. However, frequent constellations for true imaging can only be possible with at least ten (10) LEO satellites (Foelsche 1999; Foelsche and Kirchengast 2001).

Assuming straight line propagation between the transmitter and receiver, as well as constant refractivity within a pixel element, Foelsche (1999) and Foelsche and Kirchengast (2001) related observed atmospheric excess phase and refractivity with a system of linear equations to generate slant integrated water vapour (SIWV) using refractivity as the state vector. The water vapour imaging was then performed relying on the generalised inverse solution considering SIWV as observations and water vapour density as state vector. In order to handle the ill-conditioning in the equations for the imaging due to the nature of the ray geometry between the ground stations and the GNSS satellite, the GPS occultation profile was introduced as a-priori information and the solution was obtained from reconstruction using the Bayesian approach (Foelsche and Kirchengast 2001).

Considering the cost and complexity of the tomographic approach and in view of some of the limitations of ground-based GPS atmospheric profiling, our proposed methodology considers a parallel processing concept. The combination of the wet refractivity profiles simultaneously derived from ground- and space-based GPS meteorology form the basis of our proposed integration concept.

\subsection{Conceptual Formulation}

In the neutral atmosphere the excess path delay can be written as the integral of the refractivity $(N)$ along the GPS signal path. Thus, for each signal path we have (Foelsche 1999):

$\Delta L=\int_{S}(n-1) d s=10^{-6} \sum_{i} N_{i} S_{i}$

where $S_{i}$ is the ray path length from transmitter to a receiver, $N_{i}$ is the corresponding refractivity and $\Delta L$ is the excess delay. This leads to a system of linear equations:

$y=A_{x}+v$

where $y$ is the observation vector (wet delay), $A$ is the design matrix containing the length of the signal over a GPS station, while $x$ is the state vector $\left(N_{w}\right)$, and $v$ is the observation error. Nevertheless, the direct solution to Eq. (21) could be based on the generalised inverse theory. The generalised model for the observation equation:

$$
L_{a}=f\left(x_{a}\right)
$$

where $L_{a}=L+v$ is the adjusted observation and $x_{a}=x+\hat{x}$ is the adjusted parameter. Hence the solution to Eq. (21) will be of the form (Ayeni 1980):

$\hat{x}=-\left(A^{T} \cdot P \cdot A\right)^{-1} \cdot A^{T} \cdot P \cdot L$

The weight matrix $P$ is constructed as the inverse of the covariance matrix of observations (Bosy et al. 2010) hence:

$P=\sum_{L}^{-1}$

The optimal parameter (refractivity) is obtained as (Foelsche and Kirchengast 2001):

$x_{a}=x+\left(A^{T} \sum_{v}^{-1} A+\sum_{L}^{-1}\right)^{-1} A^{T} \sum_{e}^{-1}\left(L-A x_{L}\right)$

where $x$ is the vector of estimated parameters, $x_{a}$ is the state vector (i.e., the wet refractivity), $\sum_{v}^{-1}$ and $\sum_{x}^{-1}$ are the inverse covariance matrix of measurement error and the estimated parameter respectively. The covariance matrix of the optimised state vector $\sum_{x_{a}}$ can be obtained as:

$\sum_{x_{a}}=\left(A^{T} \sum_{v}^{-1} A+\sum_{L}^{-1}\right)^{-1}$ 


\section{THE CONCEPTUAL APPROACH FOR THE G-MEM}

In order to develop the G-MeM concept, a new strategy for optimal atmospheric water vapour estimation is proposed. This approach involves simultaneous estimation of atmospheric parameters from ground- and space-based GPS data processing. The conceptual design for the integration approach is as shown in Fig. 3.

The methodology for realising this concept is divided into four phases (Fig. 4): (1) data input and sources, (2) data processing and estimation, (3) integration and optimisation strategy, and (4) analysis and evaluations.

Phase 1. Data input and sources: The primary data are ground- and space-based GPS positioning data and surface meteorological data (atmospheric temperature and pressure). Upper air observations from radiosonde or NWP models (water vapour profile, refractivity profile etc.) will be obtained for analysis and validation. This proposed approach will utilise the GPS continuously operating reference station (CORS) network known as ISKANDARnet [established by Universiti Teknologi Malaysia (UTM) mainly for real-time surveying applications (Shariff et al. 2010)]. One of the stations (ISK1) is currently equipped with a surface meteorological sensor which collects and streams both GPS and surface meteorological data in real-time to the GNSS and Geodynamics (UTM G\&G) research group control centre. In order to meet the requirements for near-real-time GPS meteorology over Peninsular Malaysia, this concept takes advantage of the existing research collaboration between UTM G\&G and the Malaysian Space Agency (ANGKASA) through which the ISKANDARnet is currently being expanded. Some of the new stations currently being constructed are strategically sited close to meteorological stations. The CORS contributed by ANGKASA include AGLG, AGKB, and AGKS. Details of the proposed GPS/MET stations and their distribution across Peninsular Malaysia are given in Table 1 and Fig. 5 respectively.

For the space-based component, GPS data from LEO missions will be processed in post-mission and real-time mode by the respective mission centres and other International GNSS Service (IGS) analysis centres. These are freely accessible for research and other uses. Two such centres are the joint mission centre for FORMOSAT3/COSMIC mission [i.e., COSMIC data Analysis and Archival Centre (CDAAC) in Boulder, USA and the Taiwan Analysis Centre for Cosmic (TACC)].

Phase 2. Data processing and parameter estimation: This phase will implement the parallel processing scheme. Two components are involved; the ground-based GPS processing system and the space-based occultation system. The methodology for our proposed ground-based system follows the principle of direct ground-based GPS profiling of atmospheric refractivity as outlined by Lin et al. (2011).
Our approach utilises the data double-differencing (DD) approach to facilitate the estimation of accurate hourly ZPD. The parameter settings for the proposed processing strategy are detailed in Table 2.

The Bernese GPS processing software version 5.0 will be used. Although; the software was designed to operate in a post-mission mode Dach et al. (2007), it will be customised for the proposed near-real-time mode. Values for $N_{w}$ will then be generated based on the dual exponential distribution model described by Eq. (14). Dach et al. (2007) observed that the Saastamoinen (1972) model with Niell mapping function (NMF) performs better than other models at elevation angles lower than $5^{\circ}$, while Lowry et al. (2002) and Lin et al. (2011) recommend the Hopfield hydrostatic refractivity model for estimating the hydrostatic refractivity. Therefore, these models will be adopted for this study. We seek to generate SPD from the estimated ZPD so that ZWD can be replaced with the wet delay along an individual satellite path as the slant wet delay (SWD). Hence, the ZPD will be converted to SPD using the following (Douša 2008):

$\mathrm{SPD}=m f_{h}(z) \cdot \mathrm{ZHD}+m f_{w}(z) \cdot \mathrm{ZWD}=\mathrm{SHD}+\mathrm{SWD}$

where, ZHD and SHD are the zenith and slant hydrostatic delay respectively, $m f_{h}(z)$ and $m f_{w}(z)$ are the hdrostatic and wet mapping functions respectively, and $z$ is the zenith angle of the satellite. Equation (27) will be used for estimation

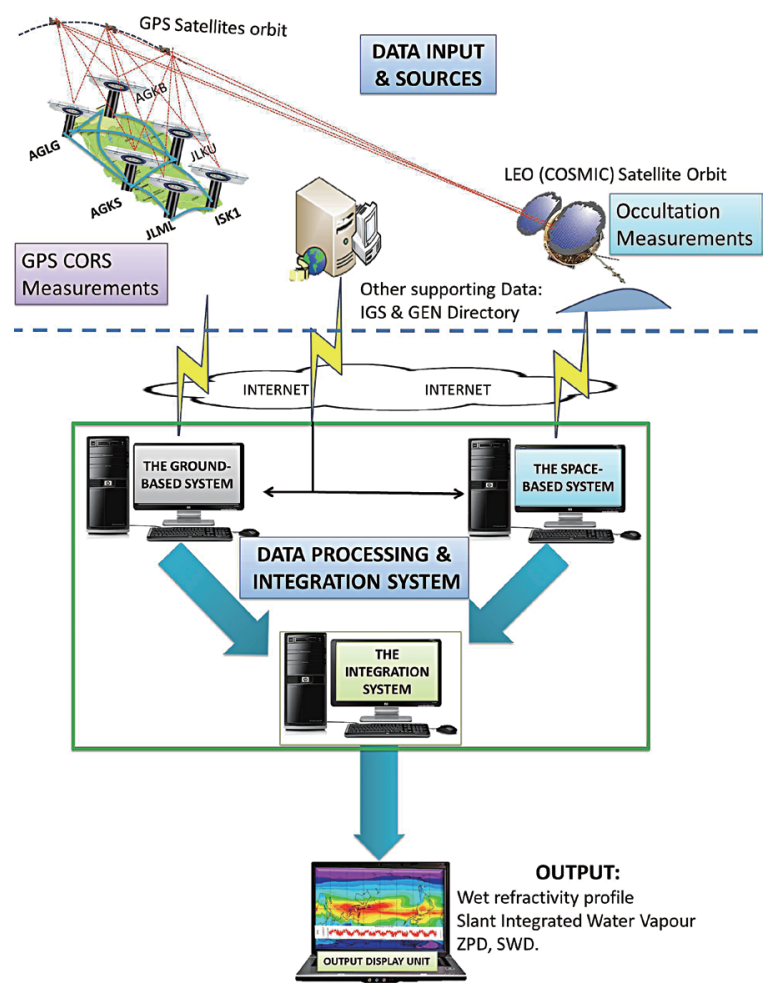

Fig. 3. The integrated GPS atmospheric sounding concept. 


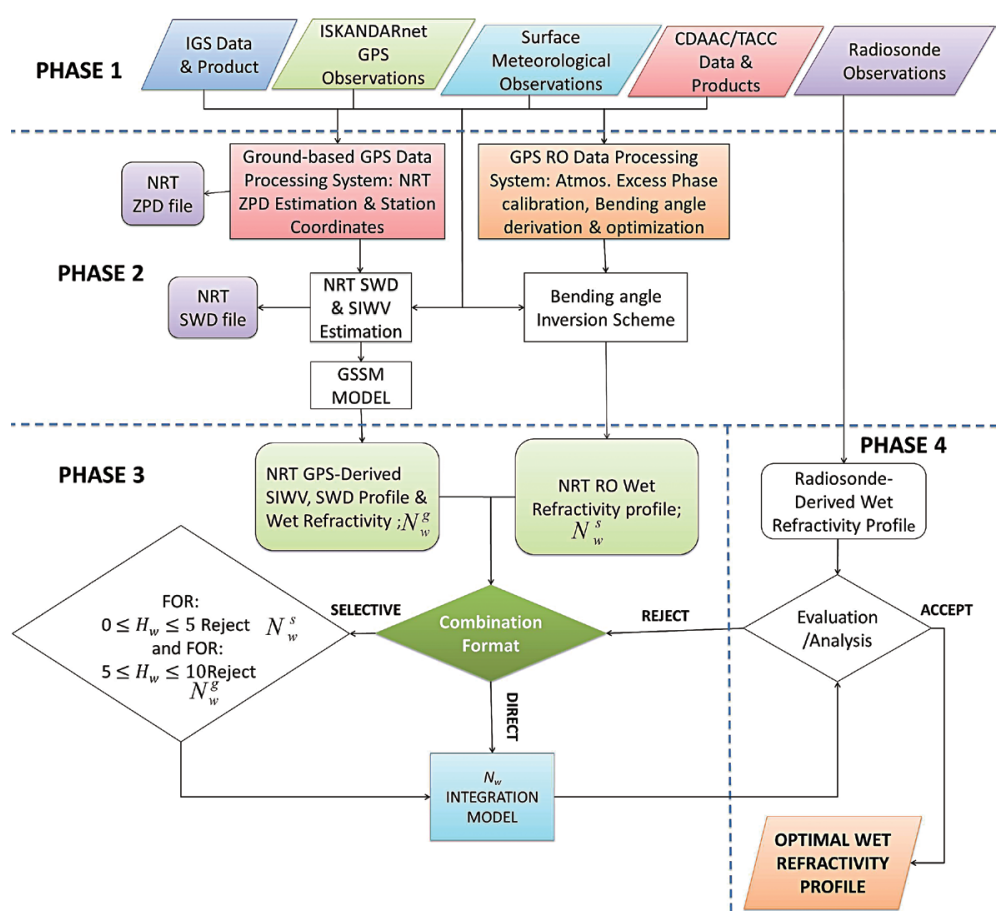

Fig. 4. The Proposed methodology for the NRT integrated GPS meteorology.

Table 1. List of GPS Meteorological Stations.

\begin{tabular}{cccccc}
\hline \multirow{2}{*}{ S/No. } & Station Name & $\begin{array}{c}\text { Station Ab- } \\
\text { brev }\end{array}$ & State & Approximate Coordinates \\
\cline { 5 - 6 } & & Latitude & Longitude \\
\hline 1 & ISKANDARnet1 & ISK1 & Johor & $01^{\circ} 33^{\prime} 37^{\prime \prime}$, & $103^{\circ} 38^{\prime} 14^{\prime \prime}$ \\
2 & Kota Bahru & AGKB & Kelantan & $06^{\circ} 09^{\prime} 55^{\prime}$, & $102^{\circ} 17^{\prime} 32^{\prime}$, \\
3 & Kuantan & JLKU & Pahang & $03^{\circ} 48^{\prime} 00^{\prime}$, & $103^{\circ} 20^{\prime} 00^{\prime}$, \\
4 & Melaka & JLML & Melaka & $02^{\circ} 10^{\prime} 44^{\prime \prime}$ & $102^{\circ} 14^{\prime} 56^{\prime}$, \\
5 & Banting & AGKS & Selangor & $02^{\circ} 49^{\prime} 33^{\prime}$, & $101^{\circ} 32^{\prime} 14^{\prime}$, \\
6 & Pulau Langkawi & AGLG & Kedah & $06^{\circ} 19^{\prime} 43^{\prime}$, & $99^{\circ} 51^{\prime} 05^{\prime}$, \\
\hline
\end{tabular}

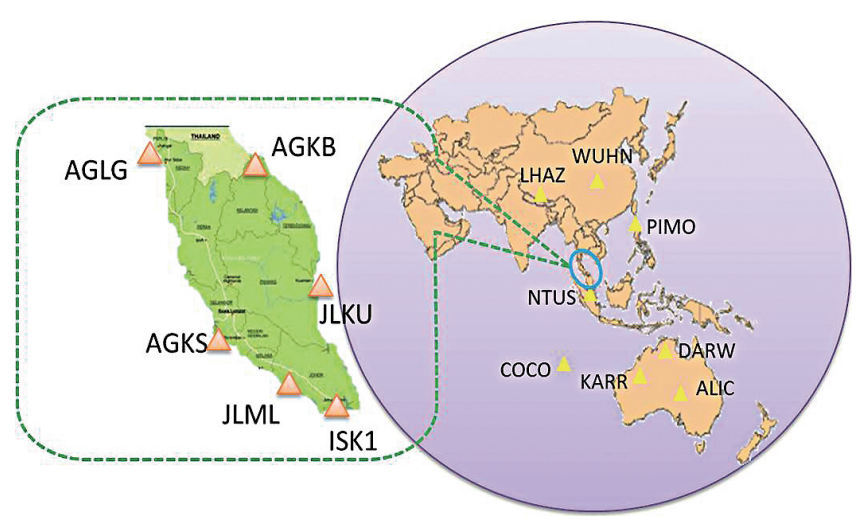

Fig. 5. Proposed GPS/MET stations and selected IGS CORS distribution. 
Table 2. Parameter settings and models for the proposed data processing strategy.

\begin{tabular}{ll}
\hline \multicolumn{1}{c}{ Parameters } & \multicolumn{1}{c}{ Processing Strategy } \\
\hline Input & Hourly \\
\hline Network design & OBS-MAX \\
\hline Elevation cut-off angle & $3^{\circ}$ \\
\hline Weighting of GPS observations & $\cos ^{2}(\mathrm{z}) ; \mathrm{z}=$ zenith angle \\
\hline Sampling rate & 30 - 180 s \\
\hline Orbits/EOP & IGS Ultra-rapid Orbit (igu) and Earth Orientation parameters (EOP) \\
\hline Station coordinates & Tightly constrained to the ITRF2008 reference frame \\
\hline Absolute antenna phase centre corrections & PHAS COD.I08, SATELLIT.I08 \\
\hline Ocean loading model & FES2004 \\
\hline Ionosphere & Double-difference ionospheric-free (IF) linear combination \\
\hline Ambiguity resolution & Fixed solution, resolved using QIF strategy \\
\hline Ionosphere model for ambiguity fixing & Global ionosphere model from CODE \\
\hline Gradient estimation & Horizontal gradient parameters: tilting at 24 h interval \\
\hline A-priori model & A-priori Saastamoinen hydrostatic model with dry nail mapping function \\
\hline Mapping function & Wet-Niell mapping function (1 h interval) \\
\hline Relative troposphere constraints & Loose \\
\hline ZPD estimates & Hourly (1 h) \\
\hline
\end{tabular}

of the SWD which can then be expressed as a function of the equivalent height of the wet term $\left(H_{w}\right)$ and used to generate $H_{w}$ with a searching algorithm.

\subsection{Searching for the Equivalent Height $\left(H_{w}\right)$ :}

The GSSM will be utilised for the search scheme and the algorithm is presented in Fig. 6 .

This method is applied to each SWD to retrieve $H_{w}$ from each GPS estimate using Eq. (16). The ground-based wet refractivity profile will then be generated utilising Eq. (14). For the space-based component, the basic principle of GPS RO has been discussed in section 2, which outlines the steps in generating the refractivity profile from GPS RO data. The equivalent SWD for all the RO-derived refractivity can be approximated using Eq. (16). Therefore, SWD and the equivalent $N_{w}$ are estimated simultaneously from the two processing systems. The sequences for these processing considerations are summarised in the process flow architecture (Fig. 7).

Phase 3. The integration and optimisation strategy: Two approaches have been identified for the integration strategy. I. The single step approach: This approach considers the profiles and SWD from the two systems as observations and solves for optimal refractivity in a least squares sense. This will be referred to as the "single-step or direct optimisation concept". In order to realise this concept, Eq. (21) is slightly modified:
$y=A x+v$

where $A$ represents the equivalent height $H_{w}$ instead of signal path length and the remaining parameters are as defined in Eq. (21). The optimal $N_{w}$ will be realised by solving Eq. (28) through a system of Eqs. (22) - (25).

II. The selective approach: The second approach involves collocating occultation points with ground-based GPS stations. Figure 8 shows a collocation scheme using the occultation points from a European Meteorological Satellite (EUMETSAT) called METOP A and ISKANDARnet (the proposed GPS/MET).

Since occultation points are traceable to the ground surface from the tangent point, the coordinate of each occultation event and GPS ground station will be used to determine their collocation, while the equivalent heights will be used to ascertain the consistency of estimated quantities from occultation and ground-based GPS.

Shi and Gao (2012) affirmed that the horizontal co-location resolution for the space-based and the ground-based GPS observation can generally be considered to range from $100-300$ km. However, Kuo et al. (2005) adopted 300 km. In this study, the co-location of $2^{0}$ (about $200 \mathrm{~km}$ ) is proposed. Thus, the following assumptions are made:

(1) A GPS occultation point $M(\varphi, \lambda)$ is said to be collocated with the GPS ground station $N(\varphi, \lambda)$ if $0 \leq M(\varphi, \lambda)-N(\varphi, \lambda) \leq \pm 2^{0}$. 
(2) At altitude above $5 \mathrm{~km}$, profiles from occultation are more consistence and reliable than those from the ground-based GPS.
(3) At altitudes below $5 \mathrm{~km}$, profiles from the ground-based GPS are more consistent and reliable than those from occultation.

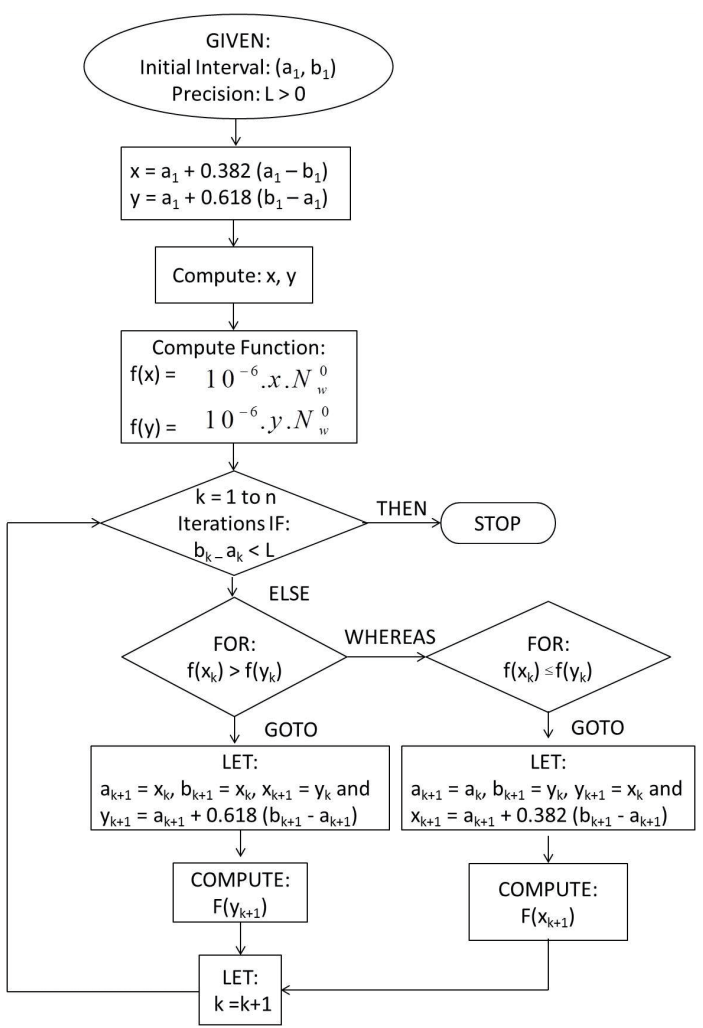

Fig. 6. Golden Section Search Method (GSSM) Algorithm (modified after Lin et al. 2011).

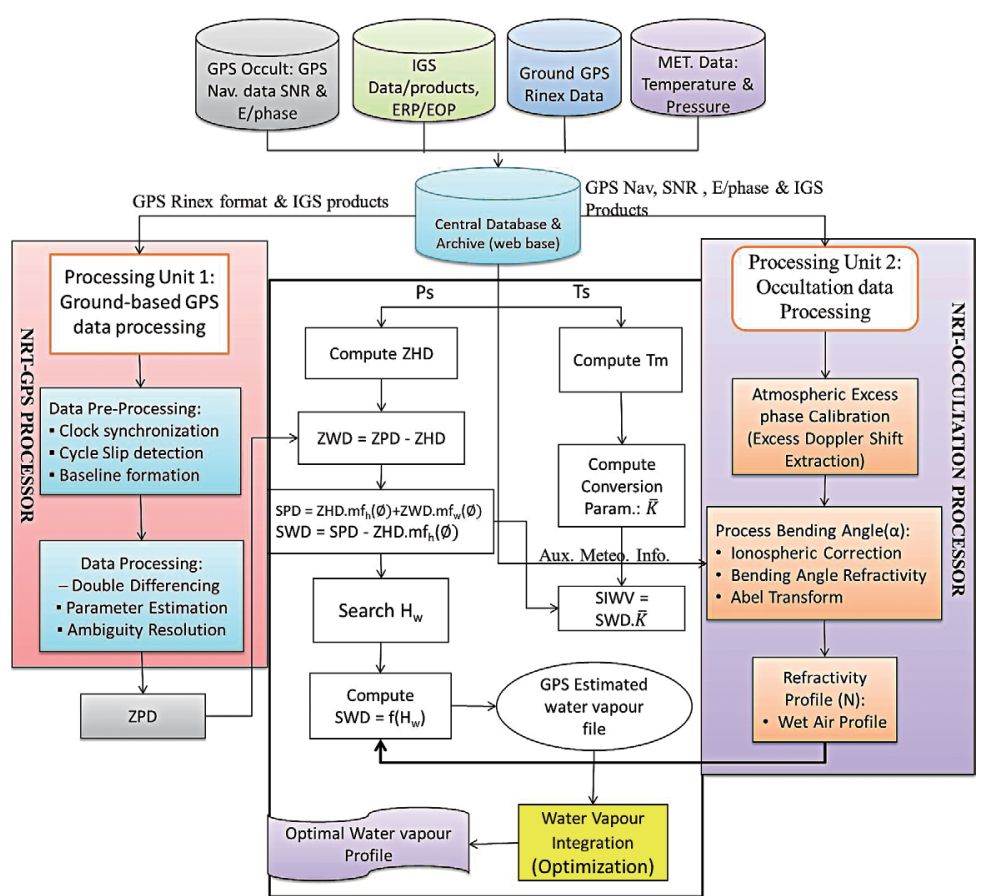

Fig. 7. The NRT Processing Architecture. 


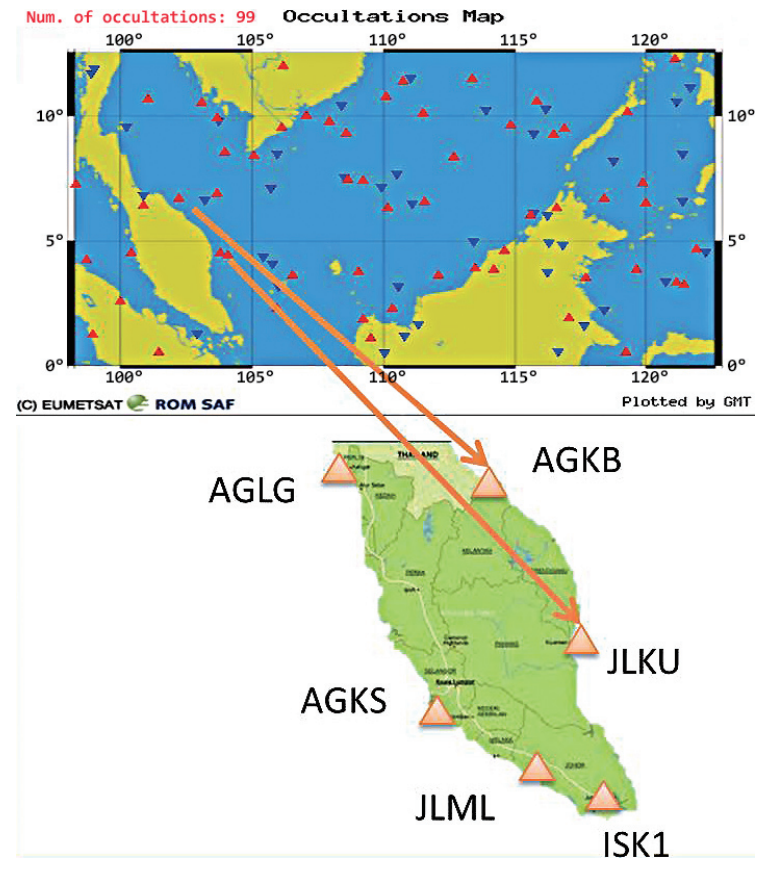

Fig. 8. Collocated occultation point [from METOP A satellite (http:// www.romsaf.org)] with ISKANDARnet for $1^{\text {st }}-30^{\text {th }}$ January 2008.

Based on these considerations, the inconsistent estimates will be marked as "bad" observations and rejected. Subsequently, the selected estimates will be utilised in the optimisation sequence as discussed above for the first approach. This will be referred to as "stepwise or selective optimisation".

Phase 4. Evaluation and analysis: The optimised refractivity will be examined using the estimate from the variancecovariance matrix [Eq. (22)]. For a near real time realisation of quality control, a refractivity field from NWP model (e.g., NCEP and ECMWF models) or high resolution readiosonde observations will be used to achieve hourly assessment of our determinations. The errors in SWD for instance, can be computed as the absolute difference between the reference or true value (e.g., from radiosonde) and the derived value from GPS:

$\operatorname{SWD}_{\text {bias }}=\left|\operatorname{SWD}\left(H_{w}\right)-\operatorname{SWD}\left(H_{w}^{\text {true }}\right)\right|$

The correlation statistics and root mean square errors of determination can be computed.

\section{ANALYSIS OF WET REFRACTIVITY FROM A SINGLE GPS SITE AND GPS RADIO OCCULTATION (RO) DATA}

In order to ascertain the feasibility of the proposed methodology, a comparative analysis of wet refractivity $\left(N_{w}\right)$ derived from the ground-based GPS and space-based GPS RO observations has been conducted. ZWD estimated from GPS data at station BANT which is one of the Malaysian real-time kinematic network (MyRTKnet) for DOY 2008 002 at 00 and $12 \mathrm{~h}$ was utilised in the GSSM model as discussed above to generate $N_{w}$ over the GPS sites. Refractivity (N) data from RO and high accuracy radiosonde observations over the same period was obtained from CDAAC and the United State National Space Administration (NASA) global radiosonde archive websites respectively. The collocation of the GPS RO and the ground-based GPS observations was based on the foregoing considerations. The coordinates of the available two occultation points, the ground GPS and radiosonde stations are depicted in Table 3.

The $N_{w}$ at the GPS site was estimated at the same altitude interval as the RO data (i.e., $100 \mathrm{~m}$ ) up to $11 \mathrm{~km}$, while $N_{w}$ from RO and radiosonde were derived from their respective refractivity data using Eq. (9). At the epoch 2008002 $00 \mathrm{~h}, \mathrm{RO}$ data was available from altitude $1.6 \mathrm{~km}$, while it is available from altitude $700 \mathrm{~m}$ at epoch $200800212 \mathrm{~h}$.

\section{RESULTS AND DISCUSSION}

The ground-based GPS refractivity at the same altitude was compared with RO using $N_{w}$ from the high accuracy radiosonde observations as truth. The variation of the wet refractivity with height from both RO and ground GPS as compared to radiosonde is depicted in Fig. 9.

The residuals computed based on Eq. (29) and the residual statistics of the derived wet refractivity over station BANT and GPS RO at 00 and $12 \mathrm{~h}$ on $2^{\text {nd }}$ January 2008 is shown in Table 4.

From Table 4 the differences between the GPS-derived $N_{w}$ and the radiosonde-derived $N_{w}$ vary from -9.25 - 21.136 $\mathrm{N}$-unit at $00 \mathrm{~h}$ UTC and $-10.63-11.714 \mathrm{~N}$-unit at $12 \mathrm{~h}$ UTC for the ground-based GPS (at station BANT) while for the GPS RO, it is $-19-9.259 \mathrm{~N}$-unit at $00 \mathrm{~h}$ UTC and $-12.078-13.999 \mathrm{~N}$-unit at $12 \mathrm{~h}$ UTC. Their linear correlation coefficients are 0.962 and 0.989 for station BANT as well as 0.964 and 0.988 for RO at 00 and $12 \mathrm{~h}$ UTC respectively. The scatter-plot is shown in Fig. 10.

From Fig. 9, it could be observed that the pattern of variation of the wet refractivity from the ground-based GPS data shows a pattern similar to that from the radiosonde than the one from GPS RO at the two epochs considered in this study. Furthermore, at the lower altitude (from $0-5 \mathrm{~km}$ ), the ground-based GPS $N_{w}$ showed better correlation with radiosonde $N_{w}$ than RO $N_{w}$ which is highly correlated with radiosonde $N_{w}$ at the altitude above $5 \mathrm{~km}$ (see Fig. 10), this is in agreement with the findings from Lin et al. $(2011,2012)$ respectively.

\section{CONCLUSION}

This paper presented a conceptual approach for the proposed integrated GPS atmospheric sounding system. A number of studies have shown that GPS meteorology is cost 
Table 3. Coordinate of occultation points, the GPS station (BANT) and radiosonde station.

\begin{tabular}{ccc}
\hline Station & Latitude & Longitude \\
\hline $1^{\text {st }}$ Occult. & $04^{\circ} 39^{\prime} 31^{\prime \prime}$ & $99^{\circ} 55^{\prime} 02^{\prime}$, \\
$2^{\text {nd }}$ Occult. & $03^{\circ} 10^{\prime} 24^{\prime \prime}$ & $99^{\circ} 55^{\prime} 13^{\prime \prime}$ \\
BANT & $02^{\circ} 49^{\prime} 33^{\prime \prime}$ & $101^{\circ} 32^{\prime} 14^{\prime}$, \\
Radiosonde & $02^{\circ} 44^{\prime} 00^{\prime}$, & $101^{\circ} 42^{\prime} 00^{\prime}$, \\
\hline
\end{tabular}
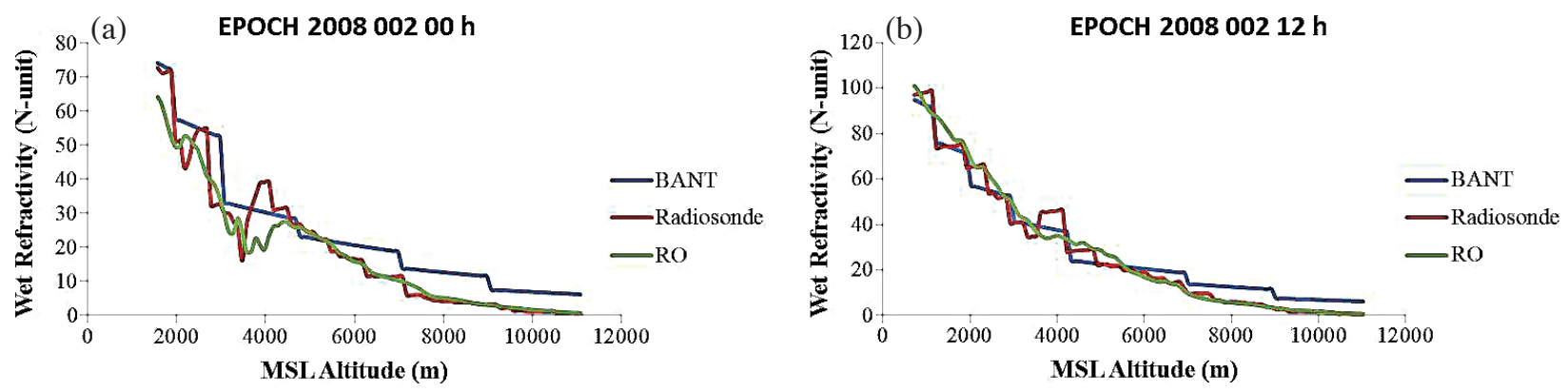

Fig. 9. Comparison of Wet refractivity profiles from RO and ground-based GPS data at BANT on day of year 2008002.

Table 4 . The residuals statistics for the wet refractivity at epoch 2008002.

\begin{tabular}{ccc|cc}
\hline & \multicolumn{2}{c|}{ Epoch 2008 002 00 h } & \multicolumn{2}{c}{ Epoch 2008 002 12 h } \\
\cline { 2 - 5 } & BANT & \multicolumn{1}{c}{ RO } & \multicolumn{1}{c}{ BANT } & RO \\
\hline MIN & -9.250 & -19.770 & -10.635 & -12.078 \\
MAX & 21.136 & 9.259 & 11.714 & 13.999 \\
MEAN & 4.836 & -1.399 & 1.714 & 0.519 \\
STDEV & 5.204 & 5.344 & 4.851 & 4.494 \\
RMS & 7.084 & 5.497 & 5.294 & 4.502 \\
\hline
\end{tabular}

(a) Radiosonde and Ground GPS Wet Ref. at $00 \mathrm{~h}$

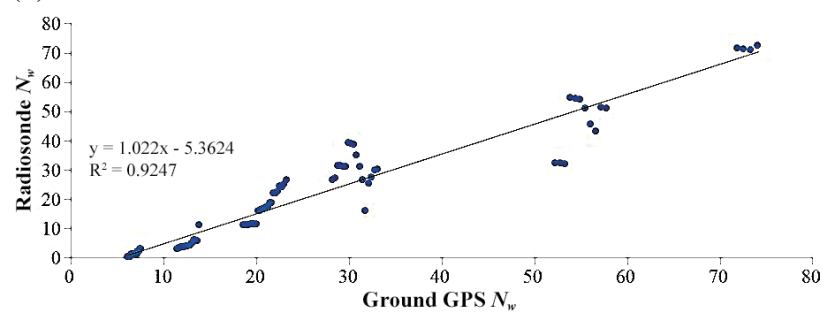

(c) Radiosonde and GPS RO Wet Ref. at $00 \mathrm{~h}$

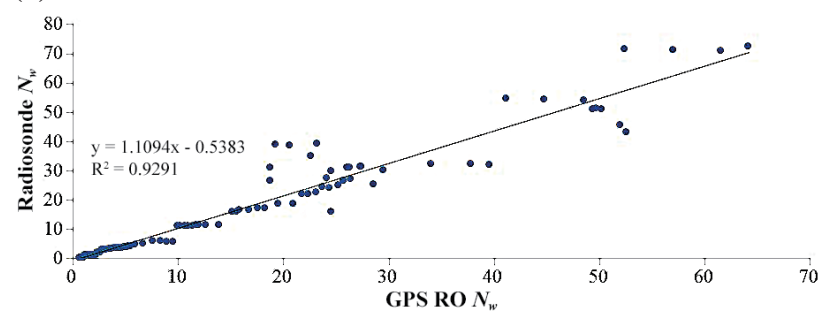

(b) Radiosonde and Ground GPS Wet Ref. at $12 \mathrm{~h}$

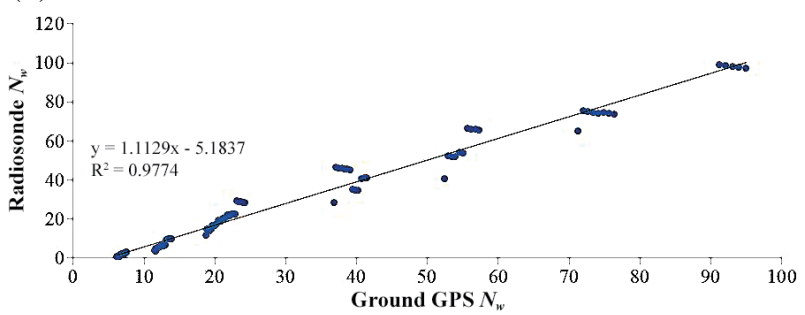

(d) Radiosonde and GPS RO Wet Ref. at $12 \mathrm{~h}$

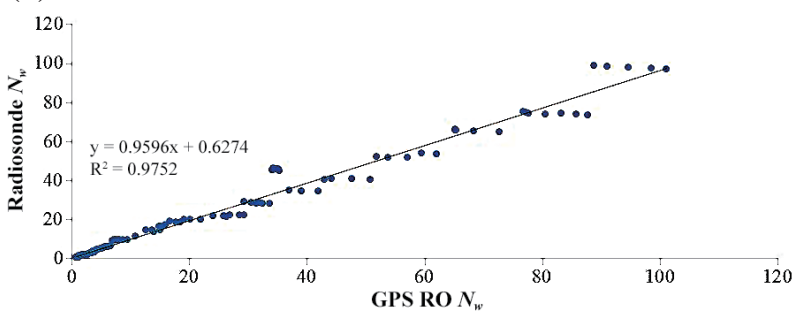

Fig. 10. Scatter-plot for comparing the GPS-derived $N_{w}$ against the radiosonde-derived $N_{w}$. 
effective, offers better spatial distribution and continuous observation irrespective of weather condition. Hence, it is a promising tool to complement other remote sensing techniques for measuring water vapour content. G-MeM based on the data combination from ground-based GPS (CORS) and space-based GPS (GPS on-board LEO satellite) observations has been proposed. The wet refractivity from these two observation techniques formed the background parameters in this proposed system. In order to establish the background assumptions for the proposed concept, ground-based and space-based (RO) GPS data were utilised simultaneously to generate the wet refractivity. It was observed from the findings that the wet refractivities from the ground-based GPS data present similar patterns and better correlation with the truth data (radiosonde) at altitudes between $0-5 \mathrm{~km}$ than that from the space-based GPS RO data. Conversely, the wet refractivities derived from the RO are more highly correlated with the radiosonde data than the ground-based GPS at altitudes above $5 \mathrm{~km}$. A detailed study involving more ground-based GPS stations is required to fully demonstrate the proposed concept and make conclusive deductions. This additional research will be considered in our subsequent publications. Results from this study are expected to be valuable for meteorologists and geodesists to explore the benefits of GPS-derived water vapour, and as a starting point for the development of a GPS-based meteorology system in Peninsular Malaysia. This will improve our knowledge of the tropospheric refractive mechanism in the equatorial region.

Acknowledgements The research is being supported by UTM University Grant (GUP) No. 08J65. The map of occultation points used was obtained from the ROM SAF online product archive. We are also grateful to CDAAC for granting us access to their data archives for this study.

\section{REFERENCES}

Arras, C., 2010: A Global Survey of Sporadic E layers based on GPS Radio Occultations by CHAMP, GRACE and FORMOSAT-3/COSMIC. Scientific Technical Report, GeoForschungsZentrum GFZ, Potsdam, Germany, $127 \mathrm{pp}$.

Ayeni, O. O., 1980: An investigation into the choice of the most appropriate least squares method for position determination. In: Fajemiroku, F. A. and O. O. Ayeni (Eds.), Proceedings of International Workshop on Geodetic Positioning, September 8-9, University of Lagos, Nigeria.

Bean, B. R., 1961: Double model of radio wave refractivity in the troposphere. Beitr. Phys. Atmos., 34, 81-91.

Bevis, M., S. Businger, T. A. Herring, C. Rocken, R. A. Anthes, and R. H. Ware, 1992: GPS meteorology: Remote sensing of atmospheric water vapor using the global positioning system.J.Geophys. Res.,97, 15787-15801, doi: 10.1029/92JD01517. [Link]

Bevis, M., S. Businger, S. Chiswell, T. A. Herring, R. A. Anthes, C. Rocken, and R. H. Ware, 1994: GPS meteorology: Mapping zenith wet delays onto precipitable water. J. Appl. Meteorol., 33, 379-386, doi: 10.1175/15200450(1994)033<0379:GMMZWD>2.0.CO;2. [Link]

Born, M. and E. Wolf, 1999: Principles of Optics: Electromagnetic Theory of Propagation, Interference and Diffraction of Light, $7^{\text {th }}$ edition, Cambridge University Press, 116-139. London, United Kingdom, 116-139, ISBN-10: 0521642221.

Bosy, J., W. Rohm, and J. Sierny, 2010: The Near real Time atmosphere model based on the GNSS and the meteorological data from the ground base augmentation system ASG-EUPOS. Int. Arch. Photogram. Rem. Sens. Spatial Inform. Sci., XXXVIII, 366-371.

Chen, Q., S. Song, S. Heise, Y. A. Liou, W. Zhu, and J. Zhao, 2011: Assessment of ZTD derived from ECMWF/NCEP data with GPS ZTD over China. GPS Solut., 15, 415-425, doi: 10.1007/s10291-010-0200-x. [Link]

Dach, R., U. Hugentobler, P. Fridez, and M. Meindl, 2007: Bernese GPS Software Version 5.0. Astronomical Institute, University of Bern, Bern, Switzerland.

Davies, O. T., C. N. Mitchell, P. S. J. Spencer, and P. A. Watson, 2001: Retrieval of the horizontal and vertical refractivity fields using GPS. Eleventh International Conference on Antennas and Propagation, IEE Conf. Publ. No. 480, Vol. 1, 288-292, doi: 10.1049/ cp:20010289. [Link]

De Haan, S., I. Holleman, and A. A. M. Holtslag, 2009: Real-time water vapor maps from a GPS surface network: Construction, validation, and applications. J. Appl. Meteorol. Climatol., 48, 1302-1316, doi: 10.1175/2008JAMC2024.1. [Link]

Douša, J., 2008: Processing of ground-based GNSS data to produce near real time (NRT) tropospheric zenith path delays (ZTD). E-GVAP (EUMETNET GPS Water Vapour Programme) Workshop, November 6, DMI, Copenhagen.

Flores, A., G. Ruffini, and A. Rius, 2000: 4D tropospheric tomography using GPS slant wet delays. Ann. Geophys., 18, 223-234, doi: 10.1007/s00585-000-0223-7. [Link]

Foelsche, U., 1999: Tropospheric water vapor imaging by combination of ground-based and spaceborne GNSS sounding data. Ph.D. Thesis, Univ. of Graz, Austria.

Foelsche, U. and G. Kirchengast, 2001: Tropospheric water vapor imaging by combination of ground-based and spaceborne GNSS sounding data. J. Geophys. Res., 106, 27221-27231, doi: 10.1029/2001JD900230. [Link]

Hajj, G. A., E. R. Kursinski, L. J. Romans, W. I. Bertiger, and S. S. Leroy, 2002: A technical description of atmospheric sounding by GPS occultation. J. Atmos. Sol.-Terr. Phys., 64, 451-469, doi: 10.1016/S13646826(01)00114-6. [Link] 
Healy, S. B. and J. R. Eyre, 2000: Retrieving temperature, water vapour and surface pressure information from refractive-index profiles derived by radio occultation: A simulation study. Q. J.R. Meteorol.Soc., 126, 16611683, doi: 10.1002/qj.49712656606. [Link]

Hirahara, K., 2000: Local GPS tropospheric tomography. Earth Planets Space, 52, 935-939.

Hopfield, H. S., 1969: Two-quartic tropospheric refractivity profile for correcting satellite data.J.Geophys, Res., 74, 4487-4499, doi: 10.1029/JC074i018p04487. [Link]

Kishore, P., M. V. Ratnam, S. P. Namboothiri, I. Velicogna, G. Basha, J. H. Jiang, K. Igarashi, S. V. B. Rao, and V. Sivakumar, 2011: Global $\left(50^{\circ} \mathrm{S}-50^{\circ} \mathrm{N}\right)$ distribution of water vapor observed by COSMIC GPS RO: Comparison with GPS radiosonde, NCEP, ERA-Interim, and JRA-25 reanalysis data sets. J. Atmos. Sol.-Terr. Phys., 73, 1849-1860, doi: 10.1016/j.jastp.2011.04.017. [Link]

Kuo, Y. H., S. V. Sokolovskiy, R. A. Anthes, and F. Vandenberghe, 2000: Assimilation of GPS radio occultation data for numerical weather prediction. Terr. Atmos. Ocean. Sci., 11, 157-186.

Kuo, Y. H., W. S. Schreiner, J. Wang, D. L. Rossiter, and Y. Zhang, 2005: Comparison of GPS radio occultation soundings with radiosondes. Geophys. Res. Lett., 32, L05817, doi: 10.1029/2004GL021443. [Link]

Kursinski, E. R., G. A. Hajj, J. T. Schofield, R. P. Linfield, and K. R. Hardy, 1997: Observing Earth's atmosphere with radio occultation measurements using the Global Positioning System. J. Geophys. Res., 102, 2342923465, doi: 10.1029/97JD01569. [Link]

Kursinski, E. R., D. Ward, A. Otarola, J. McGhee, M. Stovern, J. Hagen, W. Sisk, and H. Read, 2012: Active Temperature, Ozone \& Moisture Microwave Spectrometer (ATOMMS) status report. Sixth FORMOSAT-3/ COSMIC Data Users Workshop, October 30 - November 1, 2012, Boulder, Colorado, USA.

Lin, H., 2010: Assimilation of hyperspectral satellite radiance observations within tropical cyclones. Ph.D. Thesis, Department of Meteorology, Florida State University College of Arts and Sciences, USA.

Lin, L. K., Z. W. Zhao, Y. R. Zhang, and Q. L. Zhu, 2011: Tropospheric refractivity profiling based on refractivity profile model using single ground-based global positioning system. IET Radar Sonar Nav., 5, 7-11, doi: 10.1049/iet-rsn.2009.0167. [Link]

Lin, L. K., Z. Zhao, Q. Zhu, and Y. Zhang, 2012: Profiling tropospheric refractivity in real time, based on a relevance vector machine and single ground-based GPS receiver. Int. J. Rem. Sens., 33, 4044-4058, doi: 10.1080/01431161.2011.639403. [Link]

Liou, Y.A., Y.T. Teng, T. van Hove, and J. C. Liljegren, 2001: Comparison of precipitable water observations in the near Tropics by GPS, microwave radiometer, and radio- sondes. J. Appl. Meteorol., 40, 5-15, doi: 10.1175/15200450(2001)040<0005:COPWOI>2.0.CO;2 [Link]

Liou, Y. A., A. G. Pavelyev, J. Wickert, S. F. Liu, A. A. Pavelyev, T. Schmidt, and K. Igarashi, 2006: Application of GPS radio occultation method for observation of the internal waves in the atmosphere. J. Geophys. Res., 111, D06104, doi: 10.1029/2005JD005823. [Link]

Liou, Y. A., A. G. Pavelyev, S. F. Liu, A. A. Pavelyev, N. Yen, C. Y. Huang, and C. J. Fong, 2007: FORMOSAT-3/COSMIC GPS radio occultation mission: Preliminary results. IEEE Trans. Geosci. Remote Sensing , 45, 3813-3826, doi: 10.1109/TGRS.2007.903365. [Link]

Liou, Y. A., A. G. Pavelyev, S. S. Matyugov, O. I. Yakovlev, and J. Wickert, 2010: Radio Occultation Method for Remote Sensing of the Atmosphere and Ionosphere, In-Tech, Vukovar, Croatia, ISBN: 9789537619602, $176 \mathrm{pp}$.

Lowry, A. R., C. Rocken, S. V. Sokolovskiy, and K. D. Anderson, 2002: Vertical profiling of atmospheric refractivity from ground-based GPS. Radio Sci., 37, doi: 10.1029/2000RS002565. [Link]

Macdonald, A. E., Y. Xie, and R. H. Ware, 2002: Diagnosis of three-dimensional water vapor using a GPS network. Mon. Weather Rev., 130, 386-397, doi: 10.1175/15200493(2002)130<0386:DOTDWV>2.0.CO;2. [Link]

Mousa, A. and T. Tsuda, 2001: Retrieval of key climate variables using occultation geometry of a mountain top GPS receiver. Proceedings of the $14^{\text {th }}$ International Technical Meeting of the Satellite Division of The Institute of Navigation (ION GPS 2001), September 2001, Salt Lake City, UT, 1117-1126.

Mousa, A. and T. Tsuda, 2012: Abel inversion for deriving refractivity profile from down-looking GPS radio occultation: Simulation analysis. Arab. J. Geosci., 5, 781-787, doi: 10.1007/s12517-010-0246-7. [Link]

Musa, T. A., 2007: Analysis of residual atmospheric delay in the low latitude regions using network-based GPS positioning. Ph.D. Thesis, School of Surveying and Spatial Information Systems, University of New South Wales, Sydney, Australia.

Musa, T. A., S. Amir, R. Othman, S. Ses, K. Omar, K. Abdullah, S. Lim, and C. Rizos, 2011: GPS meteorology in a low-latitude region: Remote sensing of atmospheric water vapor over the Malaysian Peninsula. $J$. Atmos. Sol.-Terr. Phys., 73, 2410-2422, doi: 10.1016/j. jastp.2011.08.014. [Link]

Rizos, C., 2012: GNSS as an atmosphere observing technology: The IGS products \& plans. GNSS Remote Sensing Workshop, ACSER, University of New South Wales, Sydney, Australia.

Rizos, C., S. Lim, T. A. Musa, S. Ses, A. Sharifuddin, and K. Zhang, 2009: Atmospheric remote sensing using GNSS in the Australasian region: From temperate 
climates to the tropics. IGARSS, 2009 IEEE International Geoscience and Remote Sensing Symposium, Vol. 2, 12-17 July 2009, Cape Town, South Africa, doi: 10.1109/IGARSS.2009.5418076. [Link]

Saastamoinen, J., 1972: Atmospheric correction for the troposphere and stratosphere in radio ranging of satellites. Geophysical Monograph Series: The Use of Artificial Satellites for Geodesy, Vol. 15, American Geophysical Union, Washington, D.C., 247-252.

Shariff, N. S. M., T. A. Musa, K. Omar, S. Ses, and K. A. Abdullah, 2010: Performance of research-based NRTK positioning system in ISKANDAR Malaysia. 2010 Int. Symp. on GPS/GNSS, October 26-28, Taipei, Taiwan.

Shi, J. and Y. Gao, 2012: Improvement of PPP-inferred tropospheric estimates by integer ambiguity resolution. Adv. Space Res., 50, 1374-1382, doi: 10.1016/j. asr.2012.06.036. [Link]

Thayer, G. D., 1974: An improved equation for the radio refractive index of air. Radio Sci., 9, 803-807, doi: 10.1029/RS009i010p00803. [Link]

Varmaghani, A., 2012: An analytical formula for potential water vapor in an atmosphere of constant lapse rate. Terr. Atmos. Ocean. Sci., 23, 17-24, doi: 10.3319/ TAO.2011.06.28.01(A). [Link]

Wickert, J., R. Galas, G Beyerle, R. König, and C. Reigber, 2001: GPS ground station data for CHAMP radio occultation measurements. Phys. Chem. Earth, 26, 503511, doi: 10.1016/S1464-1895(01)00092-8. [Link]

Wickert, J., R. Galas, T. Schmidt, G. Beyerle, C. Reigber, C. Förste, and M. Ramatschi, 2004: Atmospheric sounding with CHAMP: GPS ground station data for occultation processing. Phys. Chem. Earth, 29, $267-$ 275, doi: 10.1016/j.pce.2004.01.015. [Link]

Wickert, J., G. Beyerle, M. Bender, Z. Deng, G. Dick, C. Falck, M. Ge, G. Gendt, S. Heise, N. Jakowski, G. Michalak, M. Ramatschi, T. Schmidt, S. Schön, and M. Semmling, 2012: GNSS atmosphere sounding. Summer School Space Geodesy, August 22, Shanghai, China.

Xie, F., D. L. Wu, C. O. Ao, and A. J. Mannucci, 2010: Atmospheric diurnal variations observed with GPS radio occultation soundings. Atmos. Chem. Phys., 10, 68896899, doi: 10.5194/acp-10-6889-2010. [Link] 